\title{
Literatura francesa de la contemporaneidad y del extremo-contemporáneo
}

\section{Monique LANDAIS CHOIMET \\ Universidad Nacional Autónoma de México}

Tratar de dar cuenta de la literatura francesa contemporánea y, más todavía, del extremo-contemporáneo, no resulta fácil por dos razones: la falta de distanciamiento y la escasez de referentes teóricos y críticos. Pero el mismo atrevimiento inherente a la empresa hizo que ésta resultara muy atractiva. De hecho, la paradoja que se impone como la figura matricial del presente artículo, bien parece estructurar el pensamiento de nuestra época: gracias a la web, nuestra realidad se percibe y se vive cada vez más en modo acrónico y atópico. Dicha peculiaridad contemporánea nos llevó a establecer una relación dialógica a través de los tiempos y espacios para resaltar cierta tendencia a la armonía y a la concordia en materia de continuum literario, más allá de las innovaciones medulares y de los préstamos tradicionales.

PALABRAS CLAVE: paradoja, dialogismo, acronía, atopía, apertura, pluralidad.

This article tries to make an account of contemporary French literature. This is no easy task, especially in the case of the extreme-contemporary, due to the lack of distance and the scarcity of critical and theoretical references. But the very audacity of such an endeavor is precisely what made it attractive. In fact, paradox emerges as the matrix figure of this article, and seems to structure the thinking of our time. Thanks to the World Wide Web, our reality is perceived and experienced in an increasingly placeless and timeless way; this contemporary peculiarity led us to establish a dialogical relationship through time and space in order to highlight a certain tendency towards harmony in terms of literary continuum, beyond core innovations and traditional loans.

KEYS WORDS: paradox, dialogism, placeless and timeless way, opening, plurality.

Dans le sixième livre du Jin Ping Mei surgit tout à coup le lettré Wen Bigu. Il n'a pas quarante ans. Il est habillé et coiffé en lettré, dents blanches, favoris de joue, favoris de menton, favoris de lèvre. Xen Qing le salue. Il le fait monter dans la salle de réception. Il le fait asseoir. Il lui offre à boire, s'incline enfin:

—Quel est votre nom?

Wen Bigu lui répond: 
—Mon humble prénom est Bigu (Nécessité-d'imiter-les-Anciens).

Mon nom personnel est Rixin (Se-renouveler-de-jour-en-jour).

Ils boivent le thé à la lumière d'une torche.

Pascal Quignard, Les Ombres errantes: 11

El siglo XXI se inserta dentro del marco de la globalización, término que tomaremos aquí desde un ángulo más cultural que económico, y que se traduce al francés con la palabra "mondialisation". Este fenómeno se caracteriza esencialmente en función de una escala planetaria como bien lo precisa Marshall Mac Luhan desde 1967, en su obra intitulada The Medium is the Message al inventar el término de "Global Village" o "Village planétaire". Entonces, conviene preguntarnos cuáles fueron los mayores impactos generados por esta nueva dimensión humana sobre la creación literaria contemporánea que surge a partir de los ochenta. ${ }^{1}$

Antes que nada, hay que recalcar la desaparición de las fronteras experimentadas como límites que sólo se podían rebasar mediante permisos otorgados por autoridades acreditadas. Si bien es cierto que las comunicaciones internacionales no esperaron la invención del sistema Internet para explayarse, resulta evidente que la implementación de esta red planetaria revolucionó los mass media al posibilitar intercambios exponenciales en todos los ámbitos: nacional o personal, intelectual o pragmático, trascendental o trivial, profesional o familiar, colectivo o íntimo, político o artístico, etcétera. Como la gran mayoría de los inventos, tiene sus lados positivos y negativos que dependen de quien los manipula. Este temor viene explícito en una entrevista que dio el escritor François Meyronnis a principios de 2014 para la emisión radiofónica Les Carnets a cargo de France Culture.

El novelista francés insiste en la noción de "capitalismo integrado" definido como la posibilidad de integrar todo a cada momento. Añade que, desde la caída del Muro de Berlín en 1989, desapareció la alternativa de pertenecer a un bloque disidente; ahora, en su totalidad, el mundo es capitalista. Tiempo y espacio se borran al ser absorbidos por la dimensión cibernética que, a su vez, tiende a negar en un nivel macro-estructural la individualidad, la singularidad y la originalidad; en una palabra,

\footnotetext{
${ }^{1}$ Según el ensayista y crítico francés Dominique Viart, la novela de François Bon Sortie d'usine marca el inicio de una nueva era en la creación literaria llamada desde entonces "contemporánea", ya que resulta imposible etiquetarla como corriente o movimiento o tendencia por su misma naturaleza diversa y expansiva. Asimismo, precisa su función eminentemente reflexiva y autorreflexiva: "À vrai dire, il faudrait appeler ces textes 'fictionnels' plutôt que 'fictifs', en tant que 'fictionnel' signifie un fonctionnement qui passe par la fiction et qui s'en sert comme d'un procédé d'investigation et d'élucidation mais n'y trouve pas sa finalité (un déploiement imaginaire ou romanesque qui vaudrait par et pour lui-même). À cet égard, on peut effectivement considérer que ces livres 'mettent la fiction en procès' dans la mesure où ils en changent la nature, où ils en interrogent la légitimité et le processus en même temps qu'ils démasquent les 'fictions' à l'œuvre dans le corps social. À ce titre, ils sont exemplaires de la profonde nature critique de la fiction contemporaine" (Viart, 2004: 303).
} 
la auténtica creatividad alterna. ${ }^{2}$ En reacción a este totalitarismo, virtual pero muy eficaz y peligroso, el escritor, cual heraldo, pone su palabra y su pluma al servicio de una libertad creadora, defensora de los derechos fundadores de nuestra nueva era, es decir, la democracia y, por ende, el discurso polémico. Al igual que François Meyronnis, otros literatos optaron por proponer innovaciones formales y/o conceptuales a fin de reavivar las letras y, por ende, eligieron un eclecticismo clarividente y convincente que se nutre del pasado y del presente para reinventar, como lo veremos en seguida, la duda y la sospecha, el género, los caracteres tipificados, los estilos canonizados y la actividad lectora-escritora vivida como función social. Tratemos de apreciar, entonces, algunos de los enriquecimientos traídos a la actualidad por ciertos autores desconcertantes, ávidos de rebeldía y libertad creadora, resistencia y genialidad legítima.

\section{El eje axiológico: la supremacía del hombre y su dignidad}

La máxima consecuencia de esta apertura sin precedentes para el tema que aquí nos interesa, es decir, el arte literario, consiste en la desintegración de los marcos fijados por los códigos teóricos. De hecho, la arácnida que asemeja la web se autogenera en modo especular desenrollándose ad infinitum en el espacio y en el tiempo; con toda razón, se habla a este propósito de ciberespacio al querer borrar cualquier tipo de limitante espacial y/o temporal puesto que un solo clic nos acerca ipso facto a cualquier punto del globo terráqueo. De ahí surgen cantidades de efectos en cuanto al manejo de la escritura y lectura literaria de los cuales sólo retendremos algunos por su estrecha vinculación con nuestra temática. A su vez, queremos por medio de nuestra reflexión, subrayar que, lejos de requerir una ruptura, la creación literaria francesa actual tiende puentes muy sólidos entre la producción presente y la milenaria. Lo que podría aparecer en primera instancia como una contradicción no hace más que confirmar la imagen de la paradoja como elemento constitutivo del sujeto contemporáneo y de su vivencia, así como de este artículo. En otras palabras, no hay que entender la paradoja como un binomio de nociones que se excluyen. De un modo diametralmente opuesto, esta figura nos lleva a pensar en función de una complementariedad que correspondería a la siguiente fórmula: "con esto y su contrario", y no "con esto sin su contrario".

Demos como ejemplo la era del recelo anunciada por Nathalie Sarraute en su obra epónima que constituye un parteaguas con el continuum literario del siglo XIX al erigir la duda como principio fundamental de todo pensamiento y experiencia existencial con el fin de contraatacar las corrientes de esta época que venían estrictamente teorizadas. Sin embargo, desde nuestra perspectiva, la nueva novela ya no representa ninguna ruptura puesto que se identifica perfectamente con la filosofía cartesiana del siglo XVII, la cual fomentaba "l'esprit d'examen" y "l'esprit critique" como bases para el apren-

\footnotetext{
${ }^{2}$ http://www.franceculture.fr/emission-les-carnets-de-1-economie-francois-meyronnis-24-qu-est-ceque-le-capitalisme-integre-2014-1. Consultado el 10 de septiembre de 2015.
} 
dizaje. Incluso podemos ver en dicha corriente cierta analogía con los Essais de Montaigne, los cuales preconizaban el cuestionamiento, la polémica y la provocación tanto a nivel literario como metaliterario. ${ }^{3} \mathrm{Si}$ bien Descartes encarna la referencia obligatoria en materia filosófica, Montaigne se impone como el espíritu libre que supo comprometerse con su tiempo y la posteridad. Profundamente integrado a su entorno sociohistórico ya que funge como alcalde de la ciudad de Bordeaux, el autor de los Essais no escatima en reflexión ni en creatividad para evidenciar la naturaleza dinámica del mundo y del propio ser humano a fin de propiciar el cambio. El escepticismo y la metamorfosis, en contra de cualquier nihilismo, se erigen con la fuerza de dos puntales dentro de la contemporaneidad y de la tradición. Digamos que este sustrato filosófico se ha mantenido en detrimento de las tentativas reiteradas de absolutismo teórico.

Es importante, pues, destacar esta continuación de intereses a través del tiempo por encima de ciertas rupturas puntuales y a pesar de transformaciones tecnológicas drásticas a fin de minimizar su impacto estereotipado (entre más información más desinformación) y enfatizar su aporte benéfico a nuestra disciplina (el enriquecimiento gracias a la diversidad y a la libertad). En resumen, tenemos, desde Montaigne, a un escritor que se analiza a sí mismo escribiendo; un literato que funge al mismo tiempo como meta-literato. Desde el punto de vista humanista, se cuida de caer en el solipsismo ya que su principal exigencia radica en el altruismo. En consecuencia, invita generosamente a su lector a adoptar su propia ética: pensar y actuar de manera coherente como fuente de re-generación constante. Desde esta perspectiva, se entiende mejor el rechazo rotundo tanto de Montaigne como de sus homólogos del siglo XXI a la teorización de ideologías, corrientes, géneros y caracteres a fin de quedar abiertos a la escritura/lectura de la complejidad y multiplicidad inherentes al universo humano. Queda claro que semejante postura abierta se adecua perfectamente al potencial creativo de todo arte destinado a decir lo indecible, a mostrar lo invisible.

Siguiendo al autor de los Essais en su voluntad de franquear los límites, transgredir los cánones coercitivos para hablar del hombre sincrónico y de su singular problemática, François Bon intenta desde los años ochenta ver ciertas realidades con una nueva mirada y desde varias perspectivas. Este escritor, nacido en 1953, lleva a cabo una experiencia muy peculiar para expresar "le basculement du siècle", cambio drástico que se entiende como una fractura dolorosa sufrida por la población trabajadora trasladada del campo donde realiza su actividad agrícola al aire libre, hacia el encierro de

\footnotetext{
${ }^{3}$ Marie-Luce Demonet estudió cuidadosamente la obra de Montaigne y nos explicó por qué Les Essais se leen como un libro infinito al proporcionarnos una "attitude étonnante et originale, puisqu'elle livre au lecteur non seulement un état, mais le cheminement vers celui-ci. Euvre où la version définitive sera toujours le brouillon de la suivante. Seule la mort interrompt le travail perpétuel de l'auteur, invitant le lecteur à poursuivre. Une telle démarche signifie déjà quelque chose du rapport entre le texte et la vérité: l'accent est mis sur la quête et sur le voyage vers le sens [...] le sens se dégage lentement de l'œuvre elle-même, avec les quatre significations que l'on peut donner au mot "essai" chez Montaigne: 1. Tentative; 2 . Expérimentation; 3. Action de goûter; 4. Euvre d'apprenti. Variation autour de la notion d'inachèvement, et démarche qui tend à rendre compte d'une dynamique du jugement, toujours renouvelée" (Demonet, 1985: 5-6).
} 
las fábricas ruidosas con sus horarios fijos y su ritmo desenfrenado. Para dar cuenta de esta fuerte quebradura socioeconómica y cultural, el autor participó él mismo en la vida laboral de la automotriz Daewo. Gracias a esta experiencia concreta durante la cual compartió las difíciles condiciones de trabajo de los obreros, pudo producir un texto que fuera un verdadero testimonio a modo de interrogante algo molesto acerca del mito todavía vigente, a saber, el bienestar social que debe de traer todo progreso industrial. Dominique Viart explica esta cautela por el hecho de que "la conscience contemporaine se situe dans une telle fracture qu'elle ne peut se contenter de dire le réel, le temps et son écoulement, sur une simple modalité nostalgique. Nourrie [...] de sciences humaines, elle pense l'impact de cet écoulement sur le psychisme individuel et social. [...] Pour la plupart des personnages, l'existence se déploie en empêchement du désir" (Viart, 1999: 121-122). A lo largo de cuatro semanas, el literato superpone dos mundos que son, por esencia, incompatibles: la escritura y la industria, la pluma y la máquina, la creatividad y la automatización. El ruido del engranaje ininterrumpido, metálico y agresivo, parece descomponer el andar del relato; el ritmo de la escritura/lectura se corta, se vuelve caótico y, rápidamente, pierde sentido. Al imponer la cadencia obrera colectiva al tempo literario individual, François Bon desconcierta a su lector, lo desplaza extrayéndolo de su zona de confort. Por su estilo innovador, híbrido ya que reúne el arte y la manufactura, el autor quiere dar cuenta de un espacio/tiempo ignorado por muchos de nosotros: la producción monstruosa de bienes en una sociedad capitalista. Siguiendo a Zola y Céline, François Bon se inscribe en lo más cruel del mundo laboral para comprometerse con sus coetáneos:

Acier alors démesurément acier, ou acier qui n'était plus qu'à sa seule mesure, puisque ayant rejoint la brûlure de son apparence et, par-delà la blessure que lui avait infligée l'homme fondant, forgeant, taillant, usinant, apparaissait lors préservé dans sa nature brute. Du sein de la virulence enflammée de son bruit, dans le lieu même bâti pour le dompter, le vaincre par tous artifices, l'acier détruisait par la racine toute tentative visant à se l'accaparer, repoussait l'homme alors hypnotisé presque, dépossédé de la possibilité de mettre fin au hurlement, figé, les mains à tenir le feu de l'air contre l'angle nu du métal, oui dans l'impossibilité de rompre avec la cause d'une douleur qu'il était pourtant seul à produire. Le bruit emplissait comme éclairs et orage l'usine, comme de faire de ce lieu le temple offert au culte et à la puissance de l'acier, et du bruit sa mystique. Ou de la crasse, des nuages d'huile et de poussière noire généreusement livrés à l'atmosphère par les jets d'air la figure multiple, torturée, pourtant absente, du dieu (Bon, 1982: 84).

Y de repente, ocurre un accidente porque uno de los obreros olvidó que la prudencia es la primera regla para sobrevivir en un ambiente donde mandan las máquinas:

Contre sa tempe sentit un choc, une flamme, et revint de derrière lui la résonance brûlante du marteau rebondissant sur l'acier des machines et cela rebondit longtemps. Comme par vagues multipliées à l'infini dans leurs échos clairs. Ne s'étonnait de rien. 
Entendit le type en blouse grise qui cria comme on rugit au milieu des blouses bleues laissez-moi me le faire [...] il sentit qu'on l'emmenait (Bon: 153).

Ideológicamente hablando, esta novela busca, por un lado, denunciar la pérdida de dignidad que implica la nueva esclavitud contemporánea y, por otro lado, otorgar una voz a los que no escriben, quizás no leen y, muchas veces, ni hablan. Es un llamado vivo a la desmitificación del progreso sea cual sea, industrial o tecnológico, $\mathrm{y}$, en el mejor de los casos, un primer paso hacia la no-indiferencia.

\section{El eje genérico: la escritura del Yo y la autoficción}

Y si dijimos que nuestro mundo per se es una paradoja asombrosa, entonces se nos permitirá ahora dirigirnos hacia un contexto diametralmente opuesto: la New York University donde Serge Doubrovsky enseñó la literatura clásica. Del duro mundo obrero donde importa la fuerza física más que nada, pasamos a la élite intelectual francesa. Vale decir que si bien sus preocupaciones no se comparan, el profesor Doubrovsky encontró también serias dificultades para conservar un equilibrio existencial de por sí bastante precario. Estas circunstancias peculiares lo llevaron a recurrir a un psicoanalista. No es de extrañar por tanto que este doble eje temático conformado por la enseñanza y la terapia haya dado lugar a su novela Fils publicada en 1977. Él mismo introduce su texto y explica el neologismo que recién acuño, "autoficción":

Fiction, d'événements et de faits strictement réels; si l'on veut, autofiction, d'avoir confié le langage d'une aventure à l'aventure du langage, hors sagesse et hors syntaxe du roman, traditionnel ou nouveau. Rencontres, fils des mots, allitérations, assonances, dissonances, écriture d'avant ou d'après littérature, concrète, comme on dit musique. $\mathrm{Ou}$ encore, autofriction, patiemment onaniste, qui espère maintenant faire partager son plaisir (Doubrovsky, 1977: 10).

Como puede apreciarse, la autoficción logra dislocar los géneros mezclándolos sin reparar ni en la apariencia caótica de la página ni en la confusión del lector que se pregunta lógicamente cuál es el código lingüístico-literario que lo guiará a través de semejante laberinto. Sin duda alguna, le será necesaria mucha paciencia para proceder a varias lecturas con el afán de distinguir los distintos hilos ("fils" en plural) que buscan reordenar al hijo ("fils" en singular) a lo largo de la novela/cura del autor/narrador/ personaje. Cabe precisar que esta novela ha permanecido como el arquetipo en su género, ya que es, a la vez, teoría y práctica. Más bien calificada de subgénero, es posible clasificarla dentro de la familia textual de la autobiografía, quedando como categoría abierta todavía en proceso de definición dado que se enriquece cada día de nuevos conceptos, formas y estilos. El experto francés en autoficción, Philippe Gasparini, intentó agrupar las diversas obras de esta variante autobiográfica desde Madame 
de La Fayette hasta Gao Xingjian y las insertó dentro de la tendencia actual de las llamadas "Escrituras del Yo", con el objetivo de eludir discusiones bizantinas (Gasparini, 2008: contraportada).

A semejanza de François Bon, Serge Doubrovsky no escatima en la innovación. Intuye que la singularidad del texto se debe representar por medio de un género nuevo, lo cual necesitaría también un lenguaje nuevo (barroco, minimalista, crudo, poético, erudito, etcétera, usados en modo simultáneo, alternado o monolítico). Dicha alteración requerida por el nuevo episteme permitiría al autor obtener el reconocimiento de los lectores, quienes aceptarían los cambios importantes realizados en relación con el género autobiográfico consagrado. Así constatamos que si Philippe Lejeune insistía sobre el efecto coercitivo del canon autobiográfico en 1967, Philippe Gasparini subraya que "notre notion du vraisemblable a considérablement évolué depuis. Nous sommes enfin prêts à admettre avec Rousseau qu'il faut, pour dire sa singularité [...] 'inventer un langage nouveau'. Ce retournement a permis au 'nouveau genre' d'obtenir une reconnaissance littéraire qui fut presque toujours refusée à ses prédécesseurs" (Gasparini, 2008: 303). Esta verbalización liberada parece otorgar una especie de máscara griega al escritor, pues entraña una revalorización de la sexualidad en el caso de Serge Doubrovsky, pero también de Annie Ernaux o Jean-Philippe Toussaint, sin olvidar en cuanto a revelación extrema de lo íntimo, las confesiones de Christine Angot. Para ilustrar mejor esta motivación por medio de un ejemplo, único pero significativo, podemos mencionar a Serge Doubrovsky que descubre y revela su bisexualidad a través de una suerte de clímax literario catártico, alcanzado gracias a la escritura de una autoficción/ epifanía escrita a la edad de cuarenta y nueve años.

Entendemos, por ende, que este nuevo subgénero nace de una doble revolución cultural, lingüística y sexual, como bien lo señala Philippe Gasparini (Gasparini, 2008: 304). Esta nueva forma escritural que entraña la introspección, llevará a otros autores a enfrentar, por ejemplo, una relación amorosa destructiva (Marguerite Duras, L'Amant), la traición sociocultural familiar y el descubrimiento del talento propio (Annie Ernaux, La Place), el autismo y el amor/odio a la madre/lengua/erotismo (Pascal Quignard, Le nom sur le bout de la langue), la depresión debida al divorcio y el ego (Marie Darrieussecq, Le mal de mer), la seducción libertina y el placer/goce de las mujeres (Philippe Sollers, Femmes), la pérdida y el imposible duelo (Camille Laurens, Philippe), la violencia paternal y el estigma traumático (Chloé Delaume, Le cri du sablier). Es menester precisar que los textos arriba mencionados atestiguan la desaparición del pacto de veracidad establecido entre el autor y el lector, propio del marco autobiográfico, para dar rienda suelta a la literarización del discurso. En esta perspectiva, Arnaud Schmitt propone el término de "autonarration" para especificar el perfil estético, epistémico y elocuente de dichos discursos:

Se dire, mais avec toute la complexité inhérente au roman et aux variations modales, polyscopiques, stylistiques propres au genre. En d'autres termes, s'autonarrer consiste à Se narrer, s'autonarrer consiste à faire basculer son autobiographie dans le 
littéraire. se dire comme dans un roman, à se voir comme un personnage même si la base référentielle est bien réelle (Gasparini, 2008: 312).

Como lo muestran las referencias teórico-críticas y novelísticas de este apartado, resulta evidente el intento realizado por varios escritores ensayistas de perfilar una variante autobiográfica desde el punto de vista de su constante metamorfosis. Sin embargo, hay que admitir que el vocablo doubrovskiano de autoficción sigue siendo usado por todos los académicos y críticos contemporáneos a pesar de las otras propuestas terminológicas: nueva autobiografía, novela autobiográfica, autonarración, novela del Yo, heterografía, escritura del Yo, etcétera. Lo relevante aquí es precisamente acentuar la irrelevante incidencia de la clásica dicotomía verdad/mentira sustituida ahora por un pacto de confianza. Este último ambiciona legitimar el discurso literario ficticio como auténtico y sincero, pero no verdadero, a fin de que cada lectura sea fuente de encuentro y construcción de interpretaciones propias a cada lector, mas no dictadas por el autor. Para respetar dicha polifonía y polisemia, el autor de autoficción rechaza la lógica causal y cronológica en beneficio de un discurso polifónico y polisémico que sigue tanto el flujo de conciencia como la reflexión metaliteraria. Con estos dos parámetros, el existencial y el conceptual, el novelista confirma la naturaleza subjetiva y objetiva de su texto y propone una deliberación acerca de la práctica escritora. Conforme a esta reivindicación artística, Pascal Quignard nos ha dado Les Ombres errantes que deambula entre confesiones, aforismos, testimonio, ensayo y meditación, enmarañados de tal suerte que la obra no encaja en ninguna categoría genérica literaria. Semejante miscelánea filosófico-literaria llevó a algunos críticos a considerarla "indécidable" (Quignard, 202: 145), sin otorgar a dicho calificativo la menor connotación peyorativa. Muy al contrario, algunos artículos periodísticos como el de Libération celebraron este Premio Goncourt 2002 por las siguientes razones:

Ils (les jurés) sont aussi bien plus dans l'air du temps qu'on ne pourrait le croire: au premier abord, ce livre ressemble à l'un de ces manuels de sagesse et de simplicité qui, depuis Sénèque et Montaigne jusqu'à leurs plagiaires modernes, donnent au lecteur contemporain l'illusion d'un supplément d'âme, de sens et d'étymologie. Jeu narcissique. Au second abord, il s'agit d'un authentique projet littéraire, un miroir égotiste dans lequel l'auteur se contemple et prépare son tombeau comme un ancien. Il y entre de la pose, de l'artifice, de la culture, du mystère, du pastiche, du latin, du mensonge, du kitsch, du ridicule parfois, bref, tout un jeu narcissique et dangereux avec la mémoire, le style et l'idée qu'un homme peut se faire de lui-même. Page à page, Quignard bâtit sa statue. Cela fait de lui un écrivain, et même un écrivain pour écrivains. ${ }^{4}$

De acuerdo con esto, queda claro que la producción literaria de la que hablamos aquí manifiesta un interés primordial por desarrollar un lado didáctico filosófico: su

\footnotetext{
${ }^{4} \mathrm{http} / / / w w w . l i b e r a t i o n . f r / c u l t u r e / 2002 / 10 / 29 /$ prix-goncourt-des-ombres-en-lumiere_419977. Consultado el 12 de septiembre de 2015 .
} 
búsqueda, ontológica y empírica, ética y estética, por establecer una relación entre el mundo y sus infinitos sentidos pretendería legar al público lector, sea escritor o no, un método heurístico pertinente para nuestros tiempos.

\section{El eje temático: mismidad y alteridad}

Con el fin de subrayar la singularidad de nuestros tiempos, el filósofo y sociólogo polaco Zigmunt Bauman los califica de "líquidos". Atribuye esta metáfora evocadora de un flujo constante e inasible, a una época en la que la nueva generación no sólo derriba las paredes sino también se empeña en invertir el organigrama convencional de las relaciones humanas, la jerarquía de las disciplinas y el ordenamiento de las palabras (Bauman, 2007: 11). Si las generaciones anteriores exigían cambios drásticos durante crisis muy bien limitadas en el espacio y el tiempo (pensemos en la revolución del 68), hoy en cambio los jóvenes parecen vivir en constante crisis como si fuera su modus vivendi. Ante tales circunstancias, la nueva generación bien parece ser "líquida" por su inagotable potencial de creatividad.

En un magnífico texto titulado Le Peintre au couteau, Ollivier Pourriol, filósofo, cineasta y novelista, nos atrae a su universo barroco, denso, fluido, donde lo fantástico de la pintura abstracta ilumina de manera momentánea pero decisiva la naturaleza opaca y fría de la ciencia (Pourriol, 2004: 30). Si se considera a esta novela desde una perspectiva pedagógica, se nota que su autor se esmera en ilustrar la siguiente máxima de La Rochefoucauld "La bonne grâce est au corps ce que le bon sens est à l'esprit" (Puzin, 1987: 356). Quizás lo inspiró el hecho de que se sabe de sobra hoy en día que el sentido común no tiene nada de común y que lo que se podía concebir como truismo exigía en realidad una nueva semantización. Sin embargo, habría que prescindir de las fórmulas de los moralistas del siglo XVII, juicios algo apresurados y cómodos, ya que fingían resolver los conflictos con sólo pronunciarlos cual si fueran enunciados performativos que realizarían ipso facto los cambios anhelados.

Desechando el tono perentorio del apotegma, Ollivier Pourriol opta por el diálogo socrático a base de intercambios pluridisciplinarios, los cuales enriquecen en modo extraordinario los conocimientos de los lectores. La estructura fragmentada de Le Peintre au couteau nos recuerda los Diálogos de Platón e imita, a la vez, una exposición de pinturas al reunir la experiencia y la esencia, el discípulo y el maestro, la imagen y el texto, los colores y las palabras, lo ordinario y lo extraordinario. Y este caleidoscopio vivo, dinámico y erudito está a cargo de dos personajes cuyo encuentro lleva a un reconocimiento de sí mismos.

Primero, tenemos a un médico cirujano ficticio que, después de unos veinte años de operar, perdió toda sensibilidad; atiende a sus pacientes como si fueran números y él un robot incansable y muy eficaz. Segundo, llega al hospital un paciente "real" ya que se trata del pintor abstracto Zao Wou Ki de origen chino que vivió en Francia y murió en Suiza en 2013. Este último juega el papel de un anciano desahuciado que, a pesar 
de sus infinitos dolores y de su debilidad física extrema, se esmera en reconciliar al médico con la humanidad por medio de un nuevo despertar al mundo sensible, afectivo y colorido. Aliando la sabiduría de su edad con el talento de su arte, logra devolverle a su doctor la integridad de ser humano gracias a la práctica paciente, lúdica y perseverante de la mayéutica. El maestro sublima la costumbre de enseñar-aprender a lo largo de toda la vida en vez de trabajar-olvidar apenas llegada la madurez. El texto que entrelaza múltiples signos semióticos (ciencia, pintura, filosofía, medicina, narrativa, anatomía, historia, poesía, etcétera) por medio de los epígrafes simula la extensión infinita del discurso humano como la capacidad creativa exponencial del texto literario. Al mismo tiempo, asevera la posibilidad de una anagnórisis a condición de que el guía sepa motivar y escuchar atenta y amorosamente a su discípulo mientras éste se abra a un nuevo interlocutor, aun inesperado y prodigioso. Durante su estancia que concuerda con una reclusión terminal, el pintor acoge de una manera sumamente hospitalaria al cirujano cuando éste se encuentra en su propio hospital y además se hace responsable de su rehabilitación a pesar de que, para él, no haya ninguna cura. Dado que su condición física le impide pintar, el artista hace alarde de un lenguaje poético que se nutre de varias fuentes acrónicas donde abundan el humor, la autocrítica, la finura, la originalidad, la inteligencia, la modestia, el propio compromiso, el respeto y el altruismo. Este texto plural intersemiótico cuyos fragmentos cortos se podrían leer a modo de un libro de horas como en la Edad Media, para meditar y cambiar, ofrece preciosos fragmentos de vida gracias a la comunicación sincera que teje apreciables lazos entre dos personajes carismáticos. En suma, entre menos previsibles sean, más convincentes se revelan. Una escritora y filósofa, Sylvie Germain, dedicó un ensayo muy ameno y significativo a propósito de la relación que se teje entre el demiurgo-autor y el personaje-protagonista, de generosidad mutua:

Tout romancier sait qu'il n'est pas "le maitre dans la maison" de son imaginaire, maison foutraque ouverte à tous les vents de l'inconscient, sujette à des flux et des reflux d'images, à des séismes, à des feux, à des éclipses. [...] Le geste d'écrire permet tout à la fois de "lire" les failles pointées par l'apparition des personnages dans l'esprit de l'auteur, de décrypter les palimpsestes de sa propre imagination et de sa mémoire [...] Le geste d'écrire est délivrance par voie d'évidement, de renoncement (Germain, 2004: 49-50).

Si se entiende de este modo el proceso que se realiza entre estas dos entidades, no es de extrañar, entonces, la tarea de investigación/elucidación/transmisión emprendida por los autores contemporáneos que pretenden dejar una enseñanza no solamente a nivel de la experiencia, para la vida diaria empírica, sino también para la reflexión filosófica a fin de tener cierta clarividencia que permita la renovación del ser. Nadie podría negar aquí que la literatura preocupada por dejar en qué pensar siempre siguió estos dos ejes de construcción, como dibujando sinusoides para unir los dos hemisferios. Obviamente, cabría resaltar otras dos direcciones de las que no quiere prescindir 
la contemporaneidad: por un lado, la observación cuidadosa de los hechos bajo diversos ángulos a fin de facilitar el análisis de los mismos e imposibilitar el juicio superficial y, por otro lado, el empeño por explicar a lo largo del relato ficticio, el nivel metaliterario del procedimiento escritura/lectura a fin de formar escritores y lectores no sólo conscientes sino actores. Frente a este fervor militante en términos de cultura y de ideología, vemos con qué entusiasmo se publica en la red un sinnúmero de textos literarios, de todo género y estilo, que patentizan la necesidad vital que el hombre tiene de decirse y de encontrar al otro por medio del discurso escrito. Es un derecho y un deber, como ya lo decía Paul Eluard:

Le droit le devoir de vivre

Il n'y aurait rien

Pas un insecte bourdonnant

Pas une feuille frissonnante

Pas un animal léchant ou hurlant

Rien de chaud rien de fleuri

Rien de givré rien de brillant rien d'odorant

Pas une ombre léchée par la fleur de l'été

Pas un arbre portant des fourrures de neige

Pas une joue fardée par un baiser joyeux

Il y aurait un homme

N'importe quel homme

Moi ou un autre

Sinon il n'y aurait rien (Eluard, 1968: 1068).

Incitar al hombre a no olvidar que es dueño de sus usos y costumbres como ser digno que es y no como cualquier avatar mediocre o títere, equivale a llevar el mundo a cuestas en esta época de consumo histérico de placeres y bienes materiales, efímeros y traidores; con todo y eso, el esfuerzo bien vale la pena. ${ }^{5}$ Semejante búsqueda de trascender lo cotidiano obsesiona en forma distinta a otros literatos que no escatiman

\footnotetext{
${ }^{5}$ En un ámbito muy distinto al nuestro, el periodístico, que sin embargo nos concierne por su poder mediático aterrador, y en otra circunstancia muy diferente, la Segunda Guerra Mundial, pero que igual nos atañe por la violencia circundante, Albert Camus aconsejaba a sus colegas el siguiente código ético: "La tarea de cada uno de nosotros es pensar bien lo que nos proponemos decir, moldear poco a poco el espíritu de nuestro periódico, escribir cuidadosamente y no perder jamás de vista esta inmensa necesidad que tenemos de volver a dar a un país su voz más íntima. Si logramos que esa voz sea la de la energía y no la del odio, la de la altiva objetividad y no la de la retórica, la de la humanidad y no la de la mediocridad, se salvarán muchas cosas y nosotros no nos sentiremos defraudados". Combat, 31 de agosto de 1944. Bien parece ser que algunos escritores franceses contemporáneos se hacen los portavoces de esta suerte de lema que, lejos de ser un dogma, sólo se legitima en la práctica dialógica diaria.
} 
sus fuerzas con tal de desengañar a las fáciles presas que constituimos para el terror mediático en nuestro andar cotidiano por el mundo.

Este fervor militante incita a luchar contra la reificación del ser, entendida como la enajenación que lleva a dejarse sustituir por los objetos, cuya obsesiva adquisición acaba con el espíritu crítico, la más mínima lucidez y el respeto que cada quien se debe a sí mismo. Empero, conviene preguntarse con qué recursos los literatos logran proponer ideas, experiencias, actitudes y hábitos distintos, en pro de una cultura del pensamiento, de la reflexión, del diálogo, del entendimiento y de la creación. Cuando decimos creación, pensamos en este detalle cotidiano, acaso una palabra, que sorprende, cambia y da sentido al nuevo día. Corresponde, en el locutor, a cierto toque original surgido de la imaginación que despierta, en el interlocutor, interés puesto que la palabra llama a la palabra. La lengua es per se comunicación, diálogo, incluso cuando es soliloquio. Ante la apremiante necesidad de combatir los mass media para preservar una expresión individualizada y constructiva, la literatura se basa, entre otros recursos, en la práctica del estilo propio.

\section{El eje estilístico: dialogismo y autenticidad}

Empecemos por recordar con Michel Lantelme que "la station debout constitue une étape essentielle au processus d'homonisation, puisqu'elle permit la libération de la main, laquelle main se prolongera ensuite dans des outils capables d'assurer à l'homme la domination progressive du monde" (Lantelme, 2008: 120). Y si no pensamos esta evolución del hombre en términos de poder adquirido para someter al otro sino de potencial creativo individual y colectivo, identificamos entonces la herramienta anhelada por el autor de la cita como la pluma, es decir, el recurso a la escritura.

Al revisar la galería de autores de la contemporaneidad, escogí a una escritora que encaja a la perfección dentro de este tema de la rebelión estilística, ansiosa por salvar la lengua. Se trata de Marie Darrieussecq. En lo que atañe a esta novelista nacida en 1969, conviene precisar que su trayectoria universitaria reúne una formación en Letras y otra en Psicoanálisis, ciencia de la que se verán importantes huellas en la novela intitulada Bref séjour chez les vivants. Si el estilo se asemeja a una especie de firma, la cual debe ser única, hay que ligarlo con la voz narrativa que lo ostenta. Es precisamente en este sentido que Claire Stolz concibe su análisis estilístico "pratiquant une sémiotique des formes littéraires, qui se constitue essentiellement, mais pas uniquement grâce à l'étude des postes (ou des postures) d'énonciation. [...] La stylistique devient alors une sémiostylistique" (Stolz, 1999: 11-12). Conforme a esta perspectiva, estudiamos con más atención la intervención y el entrelazamiento de cuatro voces narrativas, mejor dicho discursivas, dentro de la novela antes citada. Este tejido da por resultado un texto polifónico y polisémico, cuya lógica le incumbe al lector reconstruir, tomando en cuenta que el relato sigue cuatro flujos de conciencia (con sus respectivas analepsis y prolepsis) pertenecientes a la madre, Granny, y a sus tres hijas, Jeanne, Anne 
y Nore. Y por si fuera poco, al enigma del origen locutorio en ausencia total de toda referencia al emisor del enunciado, hay que agregar la carencia de puntuación tradicional así como la inserción de lenguas extranjeras, el español y el inglés. Como diría Roland Barthes, estamos leyendo un texto de goce: "celui qui met en état de perte, celui qui déconforte [...], fait vaciller les assises historiques, culturelles, psychologiques, du lecteur, la consistance de ses goûts, de ses valeurs et de ses souvenirs, met en crise son rapport au langage" (Barthes, 1973: 25-26). Al abordar una novela cuyo grado de transgresión resulta inusual, es obligatorio hacerse una pregunta más profunda acerca de su efecto como generadora de cambios: ¿cuál es la relevancia de las innovaciones estilísticas llevadas hasta el extremo límite del entendimiento para la epistemología ${ }^{6}$ Aunque nuestro acercamiento a este concepto será escueto dada la brevedad del presente artículo, podría dar lugar a una investigación mucho más aguda, la cual apoyaría precisamente la tesis que siempre defendemos: la defensa de la legitimación de la literatura contemporánea. Pero por lo pronto, así se perfila nuestra pregunta dentro del campo epistemológico: si sabemos, por un lado, que la literatura francesa contemporánea llamada transitiva se dedica ante todo a la observación y al estudio del sujeto humano sin pretender enjuiciarlo ni teorizarlo y, por otro lado, si captamos que la ciencia del conocimiento se esfuerza en averiguar y entender los factores de orden psicológico, social e histórico que lo determinan, entonces, nuestra lectura atenta de la novela se dirigirá hacia la investigación de la génesis del discurso emitido por cada una de las protagonistas. No hay que olvidar, además, que todas poseen la misma importancia dentro de la historia contada y del relato elaborado.

Para proceder a semejante análisis es imprescindible operar un distanciamiento en relación con los personajes a fin de evitar una interpretación, diríamos, sentimental. Por ejemplo, se podría pensar que Jeanne, la hija mayor que tenía en ese entonces ocho años y al cuidado de quien los padres habían dejado al hermanito de cuatro años, emigró a Argentina sólo para no cargar con la culpa de la pérdida o afrontar cada día la mirada acusadora de su familia (Darrieussecq, 2001: 15). Esto bien puede ser un significado válido y fácil de fundamentar ya que coincide con la doxa. Mas no nos debe impedir averiguar otras vías, más lacanianas. De hecho, cuando Lacan afirma que "tout sujet s'appréhende dans une ligne de fiction" (Blanckeman, 2004:303), conviene aplicar este último término no sólo al ámbito literario sino también al psicoanalítico. En consecuencia, el lector modelo, avisado y perspicaz, preconizado por Umberto Eco, procederá a una serie de asociaciones a fin de elucidar el por qué del juego lingüístico

\footnotetext{
${ }^{6}$ No pretendemos que estas innovaciones surgieron de la nada, ni mucho menos. Como lo dijimos anteriormente, la novela contemporánea no representa una ruptura en el continuum literario, sino que se afirma como ecléctica en el sentido positivo de la palabra, es decir, enriquecedora para la nueva época. Claro que las alteraciones mencionadas aquí nos remiten a escritores considerados hoy como clásicos; pensamos, entre otros, en Claude Simon para el tejido textual, en Nathalie Sarraute para el flujo de conciencia y en Michel Butor para la sintaxis deconstruida.

${ }^{7}$ En su ensayo Lector in fabula, Umberto Eco define así la actividad lectora: "l'activité coopérative qui amène le destinataire à tirer du texte ce que le texte ne dit pas mais qu'il présuppose, promet, implique
} 
de Jeanne que oscila entre el francés y el español. En realidad, ella creía que Argentina le podía ofrecer mucho más que la distancia al darle la posibilidad de reconstruir su existencia, su ser y pensamiento, gracias a un código lingüístico que le permitiera forjarse una nueva identidad: decirse a sí misma en lengua extranjera es ser otra. De esta manera, anhelaba borrar el trauma de su memoria. Sin embargo, su intento fracasó ya que murió ahogada al derrumbarse un puente durante la estación de los monzones; cruel ironía que desmonta toda su estrategia.

En contraste, su hermana Anne, dos años menor, aunque presente en el momento de la desaparición del pequeño Pierre en la playa, optó por quedarse en Francia y dedicarse a la escritura. Lejos de querer olvidar el trágico accidente, ella quiere que sea tema para platicar y llorar entre familiares dolidos, y también que constituya la materia de su primera novela. Distinguimos ahora las reacciones diametralmente opuestas de las dos hermanas sin que sean condenadas ni elogiadas. Si a ambas conductas agregamos el síndrome de Peter Pan del que sufre Nore, la hija menor, y la obsesiva afección de la madre por sus rosas, tenemos un panorama plural, un abanico caleidoscópico digno de reflexión y meditación. Eso es tanto como decir que la pluralidad impide la aprehensión reductora simplista de un problema cualquiera cuando se trata de la naturaleza humana. En este caso preciso, se evidencia la función del estilo discursivo para revelar la singularidad del ser frente al mismo evento: Jeanne se dispersa distrayéndose con la pluralidad lingüística; Anne se focaliza en la exactitud terminológica, casi científica de su lengua; Nore se estanca toda, pensamiento y lenguaje, en una etapa infantil, divertida y despreocupada; Granny, la madre, cosifica la lengua poniéndola al servicio de la cotidianidad más trivial. Además de expresar la forma de reaccionar de cada individuo frente a un trauma, es interesante subrayar que aquí se reúnen cuatro de los combates acostumbrados que libra constantemente la lengua: el plurilingüismo sin discernimiento, la teorización esclerótica, el estancamiento estéril y la desnaturalización empobrecedora. No es de extrañar por tanto que el propósito de esta lectura plural, francamente divergente, consistirá en tratar de establecer distintas lógicas de comportamiento y de expresión, sin justificación ni condena. Llámese tolerancia, objetividad o no-indiferencia a la diferencia, según el punto de vista favorecido, dicha metodología le incumbe al lector contemporáneo que no podrá prescindir de conocimientos pluridisciplinarios a fin de ampliar su horizonte de expectativas y adaptarlo a la contemporaneidad. Solamente si se preservan la libertad y la originalidad se logrará fomentar la creatividad y la metamorfosis significativa. Dominique Rabaté resume esta concepción de la literatura legitimada de la manera siguiente:

Dans la lecture du roman, je suis appelé à m'identifier à une autre perception de la vie, à coïncider avec le point de vue mobile de la narration.Mais ce mouvement d'empathie (réglé par la distance que le narrateur installe avec les personnages), s'il

ou implicite, à remplir les espaces vides, à relier ce qu'il y a dans ce texte au reste de l'intertextualité d'où il naît et où il ira se fondre" 5 . 
peut me donner à rêver d'une autre vie, d'une vie meilleure ou plus intense, à une vie romanesque, me conduit aussi à une forme de désidentification à moi-même. Il m'amène à prendre conscience du processus même de toute identification, qui réclame pour pouvoir simplement fonctionner que je puisse en quelque sorte ne plus adhérer à moi et me projeter en autrui ou en autre chose. Il me conduit ainsi à me réinterroger en tant que sujet, et donc à apercevoir la part non-subjective de ce qui me fait être en tant que sujet (Rabaté, 2010: 110).

Esta parte no-subjetiva explicitada por Dominique Rabaté nos remite a la posibilidad de una autoconstrucción permanente del Yo en contacto con el Otro; proceso que entraña dos principios fundamentales para pensar el sujeto contemporáneo forjado por la literatura francesa contemporánea. En primer lugar, no se trata ya de definir a un ser humano como lo perseguía la ontología pasada queriendo fijar de una vez por todas su naturaleza, comportamiento y proyectos. Puesto que nuestra época se desarrolla a un ritmo frenético en medio de la relatividad, de la incertidumbre y del azar, el camino recorrido entendido como constante búsqueda se impone sobre cualquier objetivo alcanzado. Por ende, esta concepción del hombre hace irrisoria también la teleología al anclarlo dentro de su realidad diaria. En segundo lugar y a modo de corolario, la autoconstrucción del sujeto es un proceso vital y perenne imprescindible para su integración social y para su equilibrio personal. Acaso, ¿se podría decir que estamos en una etapa de constante revolución (pero no colectiva, esta vez, sino individual), en la que cada espíritu crítico se responsabiliza por instituir una suerte de remolino que impediría la instauración de cualquier nuevo dogma, sea religioso, filosófico, político o artístico, con el fin de llevar a crear un presente verdadera y constantemente nuevo?

A continuación y para concluir este artículo con lo más reciente, exploraremos una novela publicada en 2012, Tout autre de François Meyronnis, perteneciente a las tendencias del extremo-contemporáneo cuyo perfil viene esbozado por Dominique Viart bajo esta forma:

Un glissement s'opère dans la littérature autour des années 1992-1998 qui marque d'une part l'acmé de textes sur la mémoire et d'autre part l'émergence de fictions désencombrées de l'héritage, qu'il soit littéraire ou historique. Après un temps concentré sur la question de l'essence de la littérature, une autre période s'est ouverte qui s'occupe plutôt d'élargir ses espaces. [...] Plus que dans une nouvelle période littéraire, nous abordons là de libres variations autour des formes contemporaines (Viart, 2013: 207).

Siguiendo las tendencias seculares, la creación literaria presente se enorgullece de la diversidad que la enriquece. Mientras unos autores se mantienen cerca de la tradición al mismo tiempo que la refrescan con algunos toques estilísticos, temáticos, genéricos y axiológicos propios de nuestra era, como vimos a lo largo de este ensayo, otros claman con una determinación a toda prueba su rechazo al frenesí ambiental. Se sublevan en contra de la carrera desenfrenada impuesta, cual dictadura, por el proceso de competencia desalmada que, muchas veces, enaltece una actitud servil (ser vil) más que 
original, en el sentido de fiel a sí mismo. La razón de escribir de estos últimos consistirá entonces en reanimar el debate intelectual acerca de la enajenación masiva cibernética que se funda sobre el aniquilamiento de cualquier intento de pensamiento crítico $\mathrm{y}$, por lo tanto, de metamorfosis real y significativa para el porvenir de la humanidad.

\section{El eje simbólico: libertad e individualidad}

Para hacer frente a este terror mediático omnipresente y omnipotente, lenificante, los literatos blanden su única arma, la palabra. François Meyronnis reviste una importancia mayor en la lucha implacable en contra de la uniformización del hombre. Practica la provocación pura al filo de las páginas de su novela Tout autre Une confession, cuyo título se podría traducir por Totalmente otro Una confesión. Estos términos nos remiten directamente a una multitud de títulos anteriores de los que sólo citaremos Les Confessions de san Agustín y de Jean-Jacques Rousseau, inscritas en la reflexión espiritual y el género autobiográfico; Totalité et Infini, de d'Emmanuel Lévinas, y Soi-même comme un autre, de Paul Ricoeur, pertenecientes a la meditación filosófica sobre la ética y la alteridad; Ombres errantes de Pascal Quignard, La Place de Annie Ernaux y Hors Champ de Sylvie Germain, que alientan este espíritu crítico y asiduo, condición sine qua non de supervivencia honorable frente a la adversidad. De ahí la imperante necesidad de leer esta autobiografía contemporánea a la luz de nuestra herencia libresca, porque Tout autre Une confession simboliza un tejido intertextual que cada lector debería seguir armando por su propia cuenta.

Al escuchar o al leer a François Meyronnis nos viene a la mente la imagen de Diógenes, quien, un día, según cuenta la leyenda, caminaba por las calles con una linterna a plena luz del día. A un transeúnte intrigado por este inusual comportamiento que le preguntó cuál era el objeto de su búsqueda, el filósofo contestó: "Busco a un hombre". Si bien Meyronnis no vive en un tonel, es relevante precisar que eligió como segundo domicilio un café llamado El Select, que está ubicado a unos minutos de su departamento cerca de Montparnasse. Ahí pasa todas sus tardes durante veinte años; lee, platica y espera, él también, al hombre. Su sedentarismo tiene una razón clínica puesto que, además de sufrir cierto grado de autismo, padece de lo que él llama un síndrome de localización, es decir, una incapacidad para orientarse en el espacio:

De Montparnasse à mon domicile, situé près du parc Montsouris, j'effectue à pied le même trajet tous les jours, entre deux séances de travail. Si, par fantaisie, j'inverse les parcours, prenant celui de l'aller pour revenir (car les deux itinéraires diffèrent légèrement), quelques minutes de marche suffisent pour semer la confusion. Faut-il avancer par ici ou par là, je ne sais plus; ni s'il faut remonter ou descendre l'artère. Ce qui signifie: être défalqué du lieu, escamoté. Cela ressemble à une culbute dans une dimension parallèle. Je ne voudrais que suivre les trottoirs, mais, dépourvu d'antécédents spatiaux, je tombe dans une crevasse au relief d'abîme (Meyronnis, 2012: 33-34). 
Para colmar este vacío aterrador, el joven Meyronnis se aferró a los nombres, sonidos tangibles y accesibles que le eran amigables. Para él, la lengua es per se hospitalaria. Desde su temprana edad, mostró entonces claros síntomas de su diferencia y se proclamó, al mismo tiempo, disidente y rebelde. Por medio de la resiliencia, hizo de una pérdida espacial, una ganancia temporal. Lógicamente, se rehusó más tarde a participar en el ímpetu la competencia, fuera ésta escolar, universitaria o profesional, y prefirió dedicarse a la lectura-escritura no aislada sino comprometida con su entorno social, aunque fuera en un modo muy sui generis. De hecho, cuando un periodista le pregunta hoy todavía de qué vive, responde con toda objetividad que su padre le proporciona semanalmente, cuatro billetes de veinte euros que le alcanzan para la comida y los libros, pues sus necesidades son muy circunscritas. ${ }^{8}$ Fuera de la indignación que semejante cínico puede despertar en nosotros cuando sabemos que tiene cincuenta y cuatro años, nos permitiremos entrever en esta clase peculiar de sustento una inteligente y justa redistribución del capital. ¿Por qué resultaría tan absurdo pensarlo como una opción equitativa, aunque fuera minoritaria, para reducir el número nunca visto de los cinco millones de desempleados franceses? Si la política actual se caracteriza por la corrupción, el nepotismo, la irracionalidad y la total indiferencia a la injusticia cotidiana, algunas familias adineradas bien podrían asumir la supervivencia de sus progenituras y hasta fungir como mecenas para las Artes y las Letras.

Ahora bien, François Meyronnis no encomia el ocio sino un estilo de vida que podríamos llamar "decreciente" puesto que va a contracorriente al oponer una resistencia inflexible al movimiento histérico del rebaño de Panurgo que hoy, más que nunca, representamos. Siguiendo esta lógica, el escritor parisino no cae en el pesimismo y mucho menos en el nihilismo que se empeña en combatir con el ejemplo, inspirándose de su autor-fetiche, Isidore Lucien Ducasse, conde de Lautréamont, aunque consciente de los riesgos que corre al seguir los pasos de quien vivió entre total libertad, extrañeza y delirio. Pero, en realidad, parece que Meyronnis admira sobre todo la prosa violenta y poderosa del conde que impregna su propio estilo:

D'abord un moment de foudre, où la liberté la plus absolue dévale sur la tête du narrateur. Lequel éprouve dans l'instant la coïncidence du vide avec la plus grande acuité, celle qui permet l'ouverture totale de l'esprit. Ce que j'appelle l'attaque du vif...Mais cette traversée du paravent attire des forces ténébreuses. [...] Traquenard du lugubre: une part d'envoûtement, partie de tous les points de la planète...[...] Comme Ulysse, comme Énée, comme Dante, il est admis dans les contrées interdites.

Lui aussi, on lui obtient une tournée en enfer - une "saison" (Meyronnis, 2012: 123-124).

El autor se aprehende como visionario, "voyant" como lo quería Rimbaud, vigilando desde el extremo de la lucidez cual centinela siempre despierto, para gozar de una

\footnotetext{
${ }^{8} \mathrm{http} / / /$ docslide.fr/documents/supplement-le-monde-des-livres-20120323.html. Consultado el 1 de septiembre de 2015 .
} 
intensa vida y revelar la posibilidad de emprender caminos desconocidos u olvidados. En esta valiente empresa, algunos amigos lo acompañan, dentro de los cuales reconocemos a Yannick Haenel, Frédéric Badré y, sobre todo, a Philippe Sollers, quien es su editor y protector. Entendemos, entonces, que estos cuatro húsares franco tiradores juegan el papel de los "agitateurs d'idées" tan apreciados en los años ochenta, auténticos pensadores cuyo objetivo primordial consiste en disentir:

Depuis que la parole accorde ses flûtes dans ma tête, je ne me sens de parenté qu'avec le litige. Dans son sillage, les pensées me viennent et aussi les phrases. Quant à celle de Platon, je me la redis sans cesse - ce qui est grand se tient dans la tempête. Mon esprit, pour s'apparaître à lui-même, a besoin de la dissension. Si possible, la plus absolue (Meyronnis, 2012: 99).

Como puede apreciarse en esta primera incursión por la obra de François Meyronnis, se defiende una fe inquebrantable en el poder simbólico de la palabra, la cual ha de llevar a la sabiduría y al discernimiento, quizás por senderos algo quejumbrosos pero prometedores de descubrimientos valiosos para cualquiera que busque sinceramente cambios en su vida. El más preciado de éstos sería considerar que la sola lengua, oral o escrita, se instituye como el principal producto de intercambio entre el escritor y sus contemporáneos, rica, gratuita e infinitamente generosa; materia prima que los autores aquí citados esperan que trabajemos, elogiemos y respetemos de igual manera día a día como fuente vital de energía. Una de las mayores virtudes de esta postura consiste, sin duda, en recordarnos que al principio era el Verbo (abstraído de cualquier connotación religiosa pero, aún así, merecedor de su mayúscula), y no cualquier mercancía material cuyo único valor sería el económico. El Verbo fue, es y seguirá siendo el símbolo originario de la creación humana y bien vale la pena que algunos le entreguen su vida, cuerpo, mente y alma, para mantener viva la flama. A su modo único y extremo, François Meyronnis simboliza el papel del escritor lúcido y responsable, quien lucha por preservar su libertad personal esperando, por ende, que los demás sepan resguardar la suya propia:

La parole, et la nomination, cela permet à l'être qui parle à partir des traces de ses expériences, à partir du roman intérieur en cours de sa vie et non pas le traitement de masse que lui promet la planète marchandisée, de partir à la recherche des objets de son désir, de fêter des retrouvailles, ceci n'étant posible qu'à partir du détachement, de la perte, dans une perspective rythmique des expériences, à partir d'une sorte de texte inconscient très singulier auquel l'aujourd'hui est sans cesse confronté. Dans une sorte d'eccéité scotienne, c'est toujours l'être singulier qui décide si ce qui lui arrive est de qualité, très loin de la quantité. Et non pas l'extérieur colonisateur qui décide de ce qui est bien, bon, et surtout rentable. ${ }^{9}$

\footnotetext{
${ }^{9} \mathrm{http} / / /$ www.e-litterature.net/publier3/spip/spip.php?page=article5\&id_article=331. Consultado el 15 de septiembre de 2015 .
} 
A fin de cuentas, esta última lectura nos devolvió una imagen distinta de nosotros mismos, una nueva manera de vernos desde una perspectiva individual, singular, peculiar, lejos de cualquier escrúpulo o vergüenza. En este sentido, François Meyronnis no defraudó a su lector ya que permaneció fiel al título de su novela Tout autre. Creemos que aquí tenemos en nuestras manos una suerte de manifiesto ético y estético, la prueba tangible de una confesión sincera y auténtica, que preconiza el ser y el existir en contra del tener y el aparentar. Semejante militancia cultural responde a una voluntad de resistencia frente a todas las tentativas de cosificación y enajenación humana por un solo medio, la lengua como reflejo de un pensamiento exigente y creativo. Basta con escuchar al autor durante sus múltiples intervenciones en la red para cerciorarse de su entrega e integridad a la causa literaria, profundamente comprometida con la sociedad contemporánea.

Al finalizar este breve abanico literario, se nos viene a la mente la imagen del rizoma insertada al mundo de la literatura por Gilles Deleuze y Félix Guattari ${ }^{10}$ para sugerir la horizontalidad de las relaciones intertextuales así como de las interhumanas. Con el fin de ilustrar mejor esta alegoría que nos parece idónea, leamos lo que dice Guillaume Artous-Bouvet a este respecto: "Le roman passe en effet pour constituer un genre éminemment dialogique, articulant et organisant en soi la totalité de tous les autres discours (Bakhtine). Le discours (romanesque) sur la vie peut alors se trouver conçu comme l'espace de la différence — et du différend — dont l'hyper-articulation rhizomatique définit la situation même de l'humanité" (Artous-Bouvet, 2012: 262). En la actualidad, hay que entender que nuestro andar por el ciberespacio (que esperamos inteligente y estructurante) ha cambiado nuestra forma de vida, concediéndonos una mirada rejuvenecida, una mente abierta y una curiosidad siempre estimulada, que nos otorgan quizás una mayor confianza y competencia en cuanto a nuestra capacidad dialógica, la cual requiere, a su vez, una mirada extensa, una mente fraterna y una curiosidad acogedora. De esta manera, se fomentará la práctica literaria en el sentido recomendado por el poeta Jean-Michel Maulpoix: "plier les mots et les discours de la théorie aux soubresauts de la création", ${ }^{11}$ entendiendo el rol de todo lector como cocreador responsable y rebelde.

\section{Obras citadas}

Artous-Bouvet, Guillaume. 2012. L'exception littéraire. París: Belin. (L'Extrême contemporain)

BARTHES, Roland. 1973. Le plaisir du texte. París: Seuil.

Bauman, Zigmunt. 2007. Tiempos líquidos. Trad. Carmen CorRaL. México: Ensayo Tusquets Editores.

\footnotetext{
${ }^{10} \mathrm{http}: / / \mathrm{csmt}$.uchicago.edu/annotations/deleuzerhizome.htm. Consultado el 17 de septiembre de 2015.

${ }^{11} \mathrm{http}: / /$ www.maulpoix.net/elogelecture.htm. Consultado el 17 de septiembre de 2015.
} 
BlAnCKEMAN, Bruno et al. 2004. Le roman français au tournant du XXIème siècle. París: Presses Sorbonne Nouvelle.

Bon, François. 1982. París: Les éditions de Minuit.

$<$ http://csmt.uchicago.edu/annotations/deleuzerhizome.htm>.

DARRIEUSSECQ, Marie. 2001. Bref séjour chez les vivants. París: Gallimard.

Demonet, Marie-Luce. 1985. Michel de Montaigne. Les Essais. París: Puf. $<$ http://docslide.fr/documents/supplement-le-monde-des-livres-20120323. html>.

Doubrovsky, Serge. 1977. Fils. París: Gallimard. (Éditions Galilée)

ECO, Umberto. 1979. Lector in fabula. París: Grasset \& Fasquelle. (Biblio Essais)

$<$ http://www.e-litterature.net/publier3/spip/spip.php?page=article5\&id article $=331>$.

ÉLuARD, Paul. 1968. Euvrescomplètes. París: Gallimard. (La Pléiade)

$<$ http://www.franceculture.fr/emission-les-carnets-de-l-economie-francois-me yronnis-24-qu-est-ce-que-le-capitalisme-integre-2014-1>.

GASPARINI, Philippe. 2008. Autofiction. Une aventure du langage. París: Seuil. (Poétique)

Germain, Sylvie. 2004. Les Personnages. París: Gallimard. (L'un et l'autre)

LANTELME, Michel. 2008. Le roman contemporain. Janus postmoderne. París: L'Harmattan.

LEJEUnE, Philippe. 1975. Le pacte autobiographique. París: Seuil. (Points Essais) $<\mathrm{http}$ :/www.liberation.fr/culture/2002/10/29/prix-goncourt-des-ombres-enlumiere_419977>.

$<\mathrm{http}$ ://www.maulpoix.net/elogelecture.htm>.

MeYronNIS, François. 2012. Tout autre Une confession. París: Gallimard NRF. (L'Infini)

Pourriol, Ollivier. 2004. Le Peintre au couteau. París: Grasset \& Fasquelle.

PuzIN, Claude. 1987. Littérature XVIIème siècle. Textes et documents. París: Nathan.

Quignard, Pascal. 2002. Les Ombres errantes. París: Grasset \& Fasquelle.

RABATÉ, Dominique. 2010. Le Roman et le sens de la vie. Mayenne: José Corti. (Essais)

SARrAute, Nathalie. 1956. L'ère du soupçcon. París: Gallimard. (Essais)

Stolz, Claire. 1999. Initiation à la stylistique. París: Ellipses.

VIART, Dominique. 2004. "Fictions en procès", en Bruno Blanckeman, Le roman français au tournant du XXIème siècle. París: Presses Sorbonne Nouvelle. 2013. Anthologie de la littérature contemporaine française. París: Armand Colin. (Scérén) 